Research

\title{
Excess circulating angiopoietin-2 is a strong predictor of mortality in critically ill medical patients
}

\author{
Philipp Kümpers ${ }^{1}$, Alexander Lukasz¹, Sascha David ${ }^{1}$, Rüdiger Horn², Carsten Hafer ${ }^{1}$, \\ Robert Faulhaber-Walter ${ }^{1}$, Danilo Fliser ${ }^{3}$, Hermann Haller ${ }^{1}$ and Jan T Kielstein ${ }^{1}$
}

\begin{abstract}
1'Department of Nephrology \& Hypertension, Hannover Medical School, Carl-Neuberg-Strasse 1, Hannover, D-30171, Germany 2Department of Gastroenterology, Hepatology and Endocrinology, Hannover Medical School, Carl-Neuberg-Strasse 1, Hannover, D-30171, Germany ${ }^{3}$ Renal and Hypertensive Diseases, Saarland University Medical Centre, Kirrberger Straße, D-66421, Homburg/Saar, Germany

Corresponding author: Philipp Kümpers, kuempers.philipp@mh-hannover.de
\end{abstract}

Received: 22 Aug 2008 Revisions requested: 19 Sep 2008 Revisions received: 27 Oct 2008 Accepted: 21 Nov 2008 Published: 21 Nov 2008

Critical Care 2008, 12:R147 (doi:10.1186/cc7130)

This article is online at: http://ccforum.com/content/12/6/R147

(c) 2008 Kümpers et al.; licensee BioMed Central Ltd.

This is an open access article distributed under the terms of the Creative Commons Attribution License (http://creativecommons.org/licenses/by/2.0), which permits unrestricted use, distribution, and reproduction in any medium, provided the original work is properly cited.

\begin{abstract}
Introduction The endothelial specific angiopoietin (Ang)-Tie2 ligand-receptor system has been identified as a non-redundant mediator of endothelial activation in experimental sepsis. Binding of circulating Ang-1 to the Tie2 receptor protects the vasculature from inflammation and leakage, whereas binding of Ang-2 antagonises Tie2 signalling and disrupts endothelial barrier function. Here, we examine whether circulating Ang-1 and/or Ang-2 independently predict mortality in a cohort of critically ill medical patients.
\end{abstract}

Methods Circulating vascular endothelial growth factor (VEGF), Ang-1 and Ang-2 were prospectively measured in sera from 29 healthy controls and 43 medical ICU patients by immunoradiometric assay (IRMA) and ELISA, respectively. Survival after 30 days was the primary outcome studied.

Results Median serum Ang-2 concentrations were increasingly higher across the following groups: healthy controls, patients without sepsis, patients with sepsis and patients with septic shock. In contrast, Ang-1 and VEGF concentrations were significantly lower in all patient groups compared with healthy controls. Ang-2 correlated with partial pressure of oxygen in arterial blood $\left(\mathrm{PaO}_{2}\right)$ /fraction of inspired oxygen $\left(\mathrm{FiO}_{2}\right)$, tissue hypoxia, Sequential Organ Failure Assessment (SOFA) and Physiology and Chronic Health Evaluation II (APACHE II) score. Multivariate Cox regression analyses confirmed a strong independent prognostic impact of high Ang-2 as a novel marker of 30-day survival.

Conclusions A marked imbalance of the Ang-Tie system in favour of Ang-2 is present in critically ill medical patients. Our findings highlight the independent prognostic impact of circulating Ang-2 in critical illness. Ang-2 may be used as a readily available powerful predictor of outcome and may open new perspectives to individualise treatment in the ICU.

\section{Introduction}

In critically ill patients, impaired vascular barrier function is a life-threatening feature that is causally determined by the activational state of the endothelial layer. In response to numerous different stimuli, 'quiescent' endothelial cells (anti-coagulant, anti-adhesive) undergo dramatic phenotypic changes towards an 'activated', pro-coagulant, pro-adhesive state, which is paralleled by disassembly of adherence junctions (e.g. VE-cad- herin) and myosin driven cell contraction, resulting in interendothelial gap formation [1,2]. This highly regulated cascade of events results in net extravasation of fluid, a profound decrease in systemic vascular tone, collapse of the microcirculation and subsequent distributive shock, acute respiratory distress syndrome (ARDS) and eventually multiple organ dysfunction syndrome (MODS) [1,3-5]. Thus, an important goal in critical care medicine is to develop novel diagnostic and ther-

Ang: Angiopoietin; APACHE II: Acute Physiology and Chronic Health Evaluation II; ARDS: acute pulmonary distress syndrome; AUC: area under the curve; Cl: cardiac index; CRP: C-reactive protein; ELISA: Enzyme Linked Immuno Sorbent Assay; EVLWI: extravascular lung water index; FiO ${ }_{2}$ : fraction of inspired oxygen; HR: heart rate; ICU: intensive care unit; Ig: immunoglobulin; IRMA: immunoradiometric sandwich assay; ITBVI: intrathoracic blood volume index; MAP: mean arterial pressure; MODS: multiple organ dysfunction syndrome; $\mathrm{PaO}_{2}$ : partial pressure of oxygen in arterial blood; PiCCO: Pulse contour Continous Cardiac Output; ROC: receiver operator characteristics; SEM: standard error of the mean; SOFA: Sequential Organ Failure Assessment; SVRI: systemic vascular resistance index; VEGF: vascular endothelial growth factor. 
apeutic strategies to address excess endothelial activation in the intensive care unit (ICU).

In 1996, Davis and colleagues discovered the angiopoietin (Ang)-Tie2 ligand-receptor system as the second class of vascular-specific receptor tyrosine kinases (the first being the vascular endothelial growth factor (VEGF)/VEGF-receptor system) [6]. Classically understood as an important regulator in vessel maturation and remodelling, recent studies demonstrated that the Ang-Tie2 system not only regulates angiogenesis, but also controls endothelial inflammation in a nonredundant manner [7-9].

Ang-1 and Ang-2 are antagonistic ligands that bind with similar affinity to the extracellular domain of the Tie2 receptor, which is almost exclusively expressed by endothelial cells. Binding of the agonist Ang-1 to the Tie2 receptor promotes vessel integrity, inhibits vascular leakage and suppresses inflammatory gene expression [10,11]. Constitutively expressed by pericytes and vascular smooth muscle cells, Ang-1 provides a stabilisation signal $[8,12,13]$. In contrast, Ang-2 inhibits binding of Ang-1 to Tie2, thereby disrupting protective Tie2 signalling [10,13-15]. Ang-2, which is considered the dynamic part of the Ang-Tie2 ligand-receptor, is stored and rapidly released by endothelial Weibel-Palade bodies [8]. Depending on the context, Ang-2 may act as a Tie2 agonist, especially in the presence of VEGF [16-18]. Intriguingly, VEGF itself was first identified and characterised as a potent stimulator of endothelial permeability and elevated circulating levels of VEGF seem to correlate with severity of sepsis and septic shock [19-21].

So far, several studies have investigated circulating Ang-1 and Ang-2 levels in critically ill patients [21-26]. Elevated Ang-2 concentrations correlate with the severity of illness as assessed by injury severity score [22], organ failure index [24], Acute Physiology and Chronic Health Evaluation (APACHE) II scores and Sequential Organ Failure Assessment (SOFA) scores $[23,25,26]$. In a recent study, we established and validated two novel immunoassays for the detection of circulating Ang-1 and Ang-2 in critically ill patients [27]. Despite the growing body of evidence indicating a role for Ang-2 as a mediator in critically illness, the value of Ang- 2 as a predictive marker of outcome is poorly defined.

The aim of this study was to investigate the independent value of circulating Ang-1 and Ang-2 as predictors of outcome in critically ill medical patients.

\section{Materials and methods Patients}

From the ICU at the Internal Medicine Department at Hannover Medical School, Germany, a tertiary care university hospital, 43 patients were enrolled at the time of ICU admission and studied prospectively. Patients were subdivided into the fol- lowing groups: severe sepsis $(n=12)$, septic shock $(n=17)$ and critically ill patients $(n=14)$ with no evidence or suspicion of bacterial infection or sepsis (SCCM/ESICM/ACCP/ATS/ SIS definitions [28]). Enrollment was performed in a consecutive fashion after obtaining written informed consents from the patients or their legal representatives. If the patient was recovering and able to communicate, he/she was informed of the study purpose and consent was required to further maintain status as study participant. The study was performed in accordance with the declaration of Helsinki and approved by the institutional review board. There were no co-morbidities that led to exclusion, except for age younger than 18 years or older than 75 years, being pregnant and having a malignant neoplasm.

Subjects were ventilated in accordance with the ARDSNetderived protocol [29]. In 29 patients, invasive haemodynamic monitoring was performed by the Pulse contour Continous Cardiac Output (PiCCO) system (Pulsion Medical Systems, Munich, Germany) in addition to standard techniques. This device enables invasive on-line monitoring of several haemodynamic parameters, such as mean arterial pressure (MAP), heart rate $(\mathrm{HR})$, cardiac index $(\mathrm{Cl})$, systemic vascular resistance index (SVRI), intrathoracic blood volume index (ITBVI) and extravascular lung water index (EVLWI), based on a transpulmonary thermodilution technique [30,31]. All relevant laboratory and medical data, including APACHE II [32] and SOFA scores [33], were obtained at the time of enrollment. Detailed patients' characteristics, including demographic, clinical and laboratory parameters, are shown in Table 1.

\section{Controls}

Twenty-nine age- and gender-matched healthy volunteers from the Hannover Medical School staff served as controls (16 males, 13 females; age 58 (25 to 73 years)).

\section{Sampling}

Serum samples for quantification of Ang-1, Ang-2 and VEGF were obtained at the time of enrollment, immediately placed on ice, centrifuged and stored at $-80^{\circ} \mathrm{C}$. All measurements were performed in a blinded fashion by the same investigator.

\section{Quantification of circulating Ang-1 and Ang-2}

Ang-1 and Ang-2 were measured by in-house Immuno Radiometric Sandwich Assay (IRMA) and ELISA, respectively as previously described [27,34]. Polyclonal, anti-human Ang-1 affinity purified goat immunoglobulin ( $\mathrm{lg}$ ) $\mathrm{G}$ and a monoclonal anti-human Ang-1 mouse antibody were obtained from R\&D Systems (R\&D, Oxford, UK). Recombinant human Ang-1 was purchased from Sigma-Aldrich (Sigma-Aldrich, Munich, Germany). Recombinant human Ang-2 monoclonal Ang-2 antibody and anti-Ang-2 antibody were purchased from R\&D Systems (R\&D, Oxford, UK). 


\begin{tabular}{|c|c|c|c|c|}
\hline Characteristics & Total & Non-septic patients & Severe sepsis & Septic shock \\
\hline Number of patients & 43 & 14 & 12 & 17 \\
\hline Male & $25(59 \%)$ & $6(43 \%)$ & $5(42 \%)$ & $14(82 \%)$ \\
\hline Female & $18(41 \%)$ & $8(57 \%)$ & $7(58 \%)$ & $3(18 \%)$ \\
\hline Age (years, median (min - max) & 51 (21 to 73$)$ & 59 (37 to 73 ) & 51 (43 to 69$)$ & 51 (39 to 64$)$ \\
\hline \multicolumn{5}{|l|}{ Reason for medical ICU admission } \\
\hline Pulmonary & $15(35 \%)$ & $4(29 \%)$ & $3(25 \%)$ & $8(47 \%)$ \\
\hline Abdominal & $10(23 \%)$ & $2(14 \%)$ & $4(33 \%)$ & $4(24 \%)$ \\
\hline Urogenital/retroperitoneal & $3(7 \%)$ & $1(7 \%)$ & $2(17 \%)$ & $0(0 \%)$ \\
\hline Cardiac & $4(9 \%)$ & $3(21 \%)$ & $0(0 \%)$ & $1(6 \%)$ \\
\hline Cerebrovascular & $4(9 \%)$ & $4(29 \%)$ & $0(0 \%)$ & $0(0 \%)$ \\
\hline Bloodstream infections & $4(9 \%)$ & $0(0 \%)$ & $2(17 \%)$ & $2(12 \%)$ \\
\hline Miscellaneous & $3(7 \%)$ & $0(0 \%)$ & $1(8 \%)$ & $2(12 \%)$ \\
\hline Mean arterial pressure $(\mathrm{mmHg})$ & 70 (40 to 96$)$ & 67 (53 to 84$)$ & 76 (67 to 91$)$ & $72(60$ to 81$)$ \\
\hline Heart rate (bpm) & $100(50$ to 145$)$ & $102(88$ to 120$)$ & 90 (78 to 110$)$ & $106(87$ to 129$)$ \\
\hline Noradrenaline ( $\mu \mathrm{g} / \mathrm{kg} / \mathrm{min})$ & 0.19 (0.0 to 1.96$)$ & 0.025 (0.0 to 0.07$)$ & $0.115(0.02$ to 0.18$)$ & $0.57(0.32$ to 0.77$)$ \\
\hline Mechanically ventilated, no. & $36(84 \%)$ & $6(43 \%)$ & $12(100 \%)$ & $17(100 \%)$ \\
\hline $\mathrm{FiO}_{2}(\%)$ & $45(26$ to 100$)$ & $40(34.53)$ & 42 (35 to 62 ) & 50 (59 to 60$)$ \\
\hline $\mathrm{PaO}_{2} / \mathrm{FiO} 2$ & 240 (68 to 640$)$ & 269 (218 to 367$)$ & 200 (130 to 257$)$ & 190 (138 to 272$)$ \\
\hline CRP (mg/L) & $129(51$ to 268$)$ & 117 (5 to 194$)$ & $172(79$ to 304$)$ & $136(54$ to 282$)$ \\
\hline Creatinine (mmol/L) & 251 (160 to 401 ) & $116(54$ to 302$)$ & 354 (210 to 431$)$ & 273 (188 to 427$)$ \\
\hline Lactate $(\mathrm{mmol} / \mathrm{L})$ & $1.9(1.2$ to 2.9$)$ & $1.3(0.9$ to 2.0$)$ & $1.6(1.0$ to 2.1$)$ & $2.9(2.1$ to 10.6$)$ \\
\hline APACHE II score & 30 (6 to 48$)$ & 26 (17 to 30$)$ & 32 (25 to 35$)$ & 32 (29 to 38$)$ \\
\hline SOFA score & 16 (1 to 22$)$ & $8(4$ to 11$)$ & 17 (14 to 20$)$ & 18 (16 to 20$)$ \\
\hline Mortality & $25(59 \%)$ & $4(29 \%)$ & $8(67 \%)$ & $13(77 \%)$ \\
\hline
\end{tabular}

APACHE II = Acute Physiology And Chronic Health Evaluation score; CRP = C-reactive protein; $\mathrm{FiO}_{2}=\mathrm{fraction}_{\mathrm{O}}$ of inspired oxygen; ICU = intensive care unit; $\mathrm{PaO}_{2}=$ partial pressure of oxygen in arterial blood; SOFA = Sequential Organ Failure Assessment score.

\section{Quantification of circulating VEGF}

Serum VEGF was measured using a sandwich ELISA kit according to the manufacturer's instructions (R\&D Systems, Minneapolis, USA). This assay measures biologically active VEGF $_{121}$ and VEGF $_{165}$.

\section{Statistical analysis}

Differences between patients and healthy controls were evaluated using a non-parametric Kruskal-Wallis test. The MannWhitney rank sum test was used for comparison between individual groups. Correlations between variables were assessed by the Spearman rank correlation coefficient. Pearson's correlation coefficient and linear regression analysis was performed after logarithmic transformation of Ang-2 values (logAng-2). The primary outcome studied was 30-day survival and was calculated from the day of ICU admission to death. Patients who survived the follow-up period were censored at day 30. Parameters independently associated with survival were identified by univariate and multivariate Cox proportional hazards models.

Variables found to be statistically significant at a $10 \%$ level in the univariate analysis were included in the multivariate model using backward elimination. Different models were established, incorporating either Ang-2, logAng-2 or the Ang-2/ Ang-1 ratio, respectively. Two-sided $p$-values $<0.05$ were considered statistically significant for all statistical procedures used. The distribution of the time-to-event variables were estimated using the Kaplan-Meier method with log-rank testing. Receiver operator characteristics (ROC) procedures were used to identify optimal cut-off values. Data are displayed as median and range (minimum to maximum) unless otherwise stated. All statistical analyses were performed with the SPSS 
package (SPSS Inc., Chicago, IL, USA) and the GraphPad Prism software (GraphPad Prism Software Inc. San Diego, California, USA).

\section{Results}

Decreased Ang-1 and VEGF concentrations and increased Ang-2 concentrations in critically ill medical patients

Ang-1 concentrations in critically ill non-septic patients $(0.8$ $\mathrm{ng} / \mathrm{ml}, 0.5$ to $11.7 \mathrm{ng} / \mathrm{ml})$, patients with severe sepsis $(0.5 \mathrm{ng} /$ $\mathrm{ml}, 0.3$ to $18.8 \mathrm{ng} / \mathrm{ml})$ and patients with septic shock $(0.9 \mathrm{ng} /$ $\mathrm{ml}, 0.3$ to $5.5 \mathrm{ng} / \mathrm{ml}$ were markedly decreased compared with healthy controls $(56.4 \mathrm{ng} / \mathrm{ml}, 34.5$ to $71.3 \mathrm{ng} / \mathrm{ml}, \mathrm{p}<0.0001)$ (Figure 1a). Ang-1 concentrations were no different between severe sepsis, septic shock and non-septic patients.

In contrast, median serum Ang-2 concentrations were consistently increased in critically ill non-septic patients $(2.8 \mathrm{ng} / \mathrm{ml}$, 1.0 to $9.0 \mathrm{ng} / \mathrm{ml})$, in patients with severe sepsis $(16.45 \mathrm{ng} / \mathrm{ml}$, 2.7 to $39.7 \mathrm{ng} / \mathrm{ml})$ and patients with septic shock $(28.1 \mathrm{ng} / \mathrm{ml}$, 3.7 to $72.6 \mathrm{ng} / \mathrm{ml})$, compared with healthy controls $(0.9 \mathrm{ng} / \mathrm{ml}$, 0.3 to $2.6 \mathrm{ng} / \mathrm{ml}$; all $\mathrm{p}<0.0001$ versus controls) (Figure $1 \mathrm{~b}$ ). Ang-2 was higher in patients with sepsis compared with nonseptic patients (both $p<0.0001$ ). Ang- 2 concentrations were not different between patients with severe sepsis and septic shock ( $p=0.12$ ). Ang-1 and Ang-2 concentrations were neither linked to gender (Mann-Whitney test: $p=0.42$ and $p=$ 0.51 ) nor age (Spearman correlation: $p=0.83$ and $p=0.24$ ).

VEGF concentrations were markedly lower in critically ill nonseptic patients $(43.5 \mathrm{pg} / \mathrm{ml}, 4.1$ to $200.0 \mathrm{pg} / \mathrm{ml})$, patients with severe sepsis (112.7 pg/ml, 34.9 to $569.1 \mathrm{pg} / \mathrm{ml})$ and patients with septic shock $(70.5 \mathrm{pg} / \mathrm{ml}, 3.7$ to $179.9 \mathrm{pg} / \mathrm{ml}$ compared with healthy controls $(515.5 \mathrm{pg} / \mathrm{ml}, 280.6$ to $1294.0 \mathrm{pg} / \mathrm{ml}$, all $p<0.0001$ ) (Figure 1c). VEGF concentrations were no different between patients with severe sepsis, patients with septic shock and non-septic controls. VEGF concentrations were not linked to gender $(p=0.67)$ and did not correlate with age $(p$ $=0.33$ ).

\section{Circulating Ang-2 concentrations correlate with SOFA and APACHE II scores}

Linear regression analysis detected a strong association of logAng-2 concentration with APACHE II scores $\left(r^{2}=0.28, p\right.$ $=0.0003)$ and SOFA scores $\left(r^{2}=0.62, p<0.0001\right)$ (Figures $2 a, b ; n=43)$. Hypoxia has been shown to induce the release of Ang-2 from endothelial cells in preclinical models $[35,36]$. Of note, a strong correlation between Ang- 2 concentrations and lactate levels as a surrogate marker for tissue hypoperfusion and microcirculatory tissue hypoxia was detected $\left(\mathrm{r}^{2}=\right.$ $0.25, p=0.0007)$. Neither Ang-1 nor VEGF correlated with APACHE II scores, SOFA scores or C-reactive protein (CRP) levels.
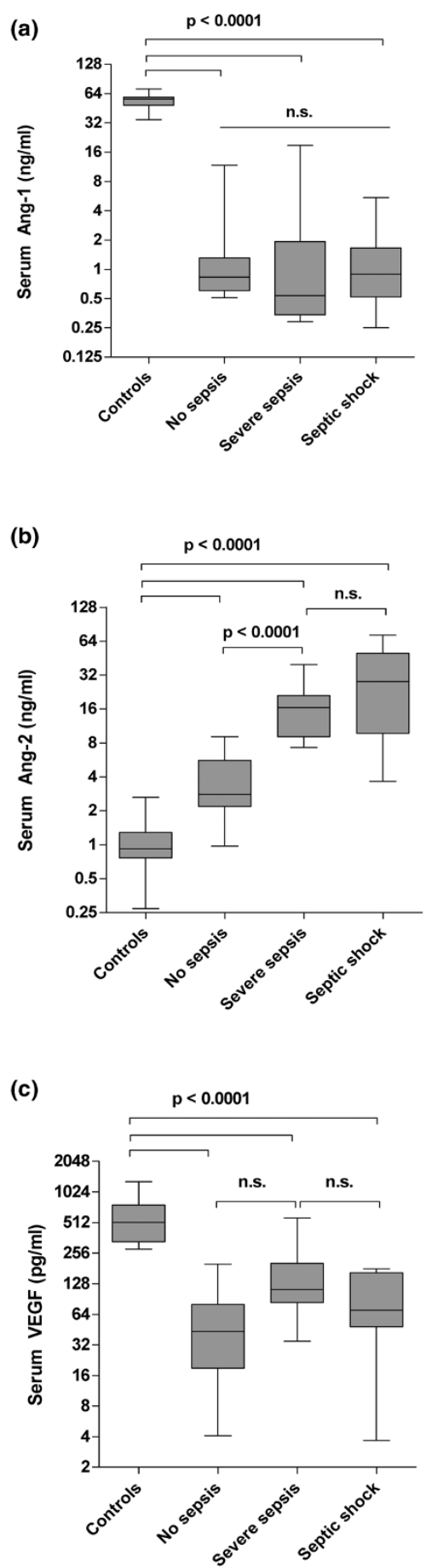

Box plots of results in healthy controls and study patients. Circulating (a) Angiopoietin (Ang) 1, (b) Ang-2 and (c) vascular endothelial growth factor (VEGF) serum concentrations in healthy controls $(n=$ 29 ), critically ill patients without infection (no sepsis; $n=14$ ), patients with severe sepsis $(n=12)$ and septic shock $(n=17)$. Horizontal bars indicate median values. 
Figure 2
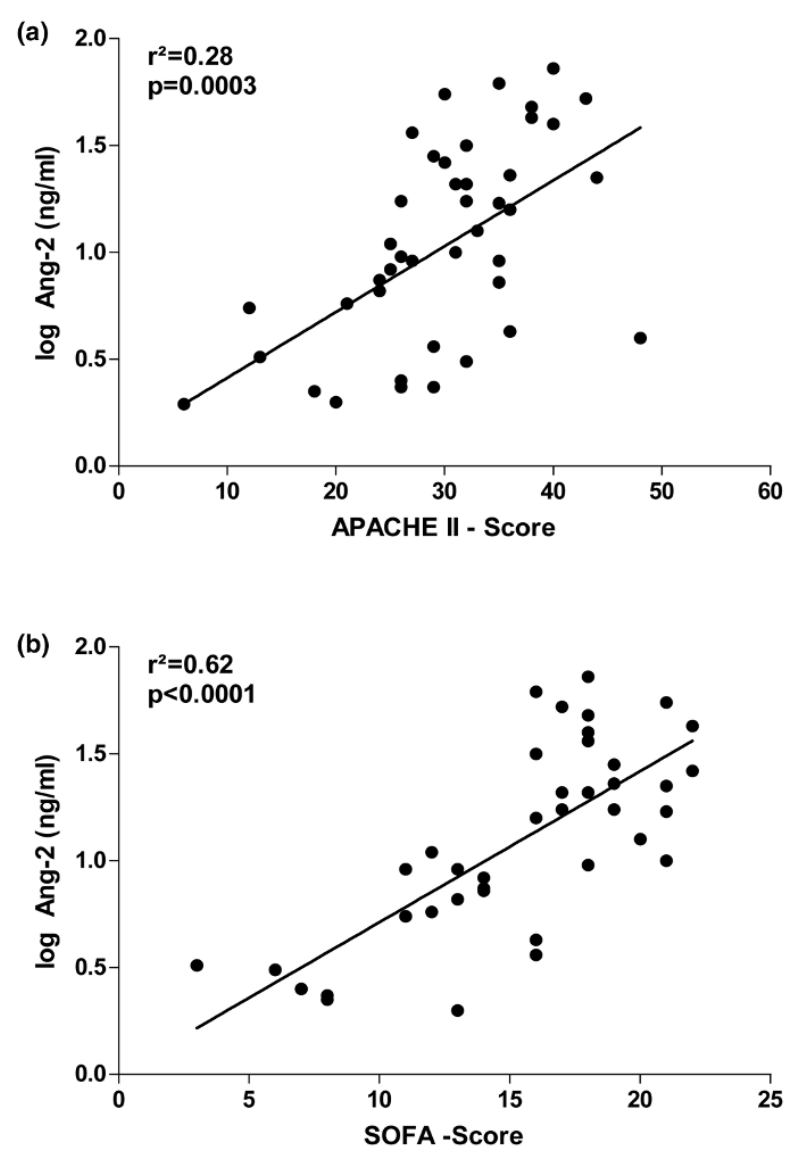

Scatter plots showing correlations of results. Correlations of Ang-2 serum concentrations with (a) the Acute Physiology and Chronic Health Evaluation (APACHE) II score and (b) the Sequential Organ Failure Assessment (SOFA) score in 43 critically ill patients (non-septic patients $(n=14)$; severe sepsis $(n=12)$ and septic shock $(n=17))$.

\section{Association of Ang-1, Ang-2 and VEGF with pulmonary function and haemodynamics}

Pre-clinical models have impressively demonstrated that the intact Ang-1/Tie2 signalling protects from ARDS in experimental sepsis [36-38]. We therefore examined the association between several parameters of haemodynamic and pulmonary function with circulating Ang-1, Ang-2 and VEGF levels. Of those, only Ang-2 showed an inverse correlation with partial pressure of oxygen in arterial blood $\left(\mathrm{PaO}_{2}\right)$ /fraction of inspired oxygen $\left(\mathrm{FiO}_{2}\right)\left(\mathrm{r}^{2}=-0.31 ; \mathrm{p}=0.046\right)$, and $\mathrm{PaO}_{2}\left(\mathrm{r}^{2}=-0.35 ; \mathrm{p}\right.$ $=0.023$ ) as surrogate markers for ventilator support and pulmonary function. No association was seen for peak airway pressure $(p=0.6)$ or positive end expiratory pressure levels ( $p$ $=0.45$ ). In addition to routine invasive haemodynamic monitoring $(n=43), 29$ ventilated patients without atrial fibrillation qualified for detailed haemodynamic assessment by transpulmonary thermodilution technique (PiCCO system). Surpris- ingly, none of the measured angiogenic factors correlated with any of the haemodynamic parameters (MAP, Cl, EVLWI, ITBVI, SVRI, vasopressor dose or central venous pressure; data not shown). The same results were obtained for invasive routine monitoring in all 43 patients (data not shown).

\section{Circulating Ang-2 predicts mortality in critically ill patients}

To determine the relation between Ang-2 levels at admission and mortality, we initially performed univariate Cox proportional hazards analyses. In our whole cohort of critically ill medical patients, age, gender or the presence of sepsis did not show prognostic significance for survival (Table 2). The same was true for MAP, HR, CVP, urine output, noradrenaline dose, $\mathrm{FiO}_{2}, \mathrm{PaO}_{2} / \mathrm{FiO}_{2}$, thrombocytes, bilirubin, CRP and VEGF (Table 2). Among the tested variables, lactate $(p=0.006)$, APACHE II score $(p=0.013)$, SOFA score $(p=0.038)$ and the amount of circulating Ang-2 $(p=0.001)$ displayed prognostic significance (Table 2).

Subsequently, the following variables were found to be statistically significant at a $10 \%$ level in the univariate analysis and subjected to multivariate Cox regression analysis: lactate, APACHE II score, SOFA score and circulating Ang-2 (Table 2). Except for Ang-2 ( $p=0.002)$, all other variables did not remain significant in the multivariate setting (lactate $(p=$ $0.111)$, APACHE II score $(p=0.154)$, SOFA score $(p=$ $0.167))$. The same results were obtained when either logAng$2(p=0.003)$ or the Ang-2/Ang-1 ratio $(p=0.036)$ were tested instead of Ang-2 (Table 2). Thus, circulating Ang-2 was identified as a strong, independent prognostic factor for 30day survival in our cohort of critically ill medical patients. Given the context-dependent synergistic effects of Ang-2 and VEGF, we analysed various ratios incorporating Ang-1, Ang-2 and VEGF (data not shown). Except for the Ang-2/Ang-1 ratio, none of these models reached statistical significance (Table 2).

Ang-2 yielded an area under the ROC curve (AUC) value of 0.79 (standard error of the mean $(\mathrm{SEM})=0.07 ; 95 \%$ confidence interval $=0.65$ to $0.93 ; p=0.001$ ). For comparison, the APACHE II score yielded an AUC value of 0.75 (SEM $=0.08$; $95 \%$ confidence interval $=0.59$ to $0.91 ; p=0.005$ ). A median circulating Ang-2 of more than $11.08 \mathrm{ng} / \mathrm{ml}$ predicted death with a specificity of $74 \%$ ( $95 \%$ confidence interval $=57$ to 86 ) and a sensitivity of $67 \%$ ( $95 \%$ confidence interval $=54$ to 77 ). The odds ratio for 30-day mortality was 5.6 (95\% confidence interval $=1.5$ to 20.5 ), positive and negative predictive values were $76 \%$ (95\% confidence interval $=61$ to 88 ) and $64 \%$ (95\% confidence interval $=49$ to 75 ), respectively.

Figure 3 illustrates the Kaplan-Meier curves of 30-day survival stratified to Ang-2 (less versus higher than median (11.08 ng/ $\mathrm{ml})$ ). Log rank test confirmed statistical significance for Ang-2 $(p=0.009)$. Accordingly, the hazard for Ang-2 (> median) in 
Table 2

\begin{tabular}{|c|c|c|c|c|c|c|}
\hline \multirow[b]{2}{*}{ Variables } & \multicolumn{3}{|c|}{ Univariate } & \multicolumn{3}{|c|}{ Multivariate } \\
\hline & HR & $95 \% \mathrm{Cl}$ & $p$ value & HR & $95 \% \mathrm{Cl}$ & $P$ value \\
\hline Age (years) & 1.528 & 0.694 to 3.364 & 0.288 & & & \\
\hline Gender (m/f) & 1.007 & 0.983 to 1.031 & 0.577 & & & \\
\hline Sepsis (yes/no) & 2.688 & 0.918 to 7.874 & 0.072 & 1.004 & 0.154 to 6.553 & 0.997 \\
\hline MAP $(\mathrm{mmHg})$ & 0.981 & 0.954 to 1.009 & 0.186 & & & \\
\hline Heart rate (bpm) & 0.995 & 0.976 to 1.014 & 0.583 & & & \\
\hline Noradrenaline $(\mu \mathrm{g} / \mathrm{kg} / \mathrm{min})$ & 1.433 & 0.695 to 2.954 & 0.330 & & & \\
\hline $\mathrm{FiO}_{2}(\%)$ & 1.002 & 0.980 to 1.025 & 0.873 & & & \\
\hline $\mathrm{PaO}_{2} / \mathrm{FiO}_{2}$ & 1.001 & 0.997 to 1.005 & 0.737 & & & \\
\hline $\mathrm{CRP}$ (mg/L) & 0.998 & 0.995 to 1.002 & 0.364 & & & \\
\hline Lactate $(\mathrm{mmol} / \mathrm{L})$ & 1.105 & 1.029 to 1.185 & $0.006^{*}$ & 1.064 & 0.986 to 1.148 & 0.111 \\
\hline APACHE II score & 1.060 & 1.012 to 1.110 & $0.013^{*}$ & 1.040 & 0.985 to 1.099 & 0.154 \\
\hline SOFA score & 1.107 & 1.006 to 1.219 & $0.038^{\star}$ & 1.073 & 0.971 to 1.185 & 0.167 \\
\hline VEGF (pg/ml) & 1.000 & 0.997 to 1.004 & 0.962 & & & \\
\hline Ang-1 (ng/ml) & 1.010 & 0.918 to 1.111 & 0.840 & & & \\
\hline Ang-2 (ng/ml)a & 1.034 & 1.013 to 1.056 & $0.001^{*}$ & 1.033 & 1.012 to 1.055 & $0.002^{*}$ \\
\hline Ang-2 $(\log 10)^{a}$ & 4.383 & 1.628 to 11.802 & $0.003^{*}$ & 4.284 & 1.627 to 11.281 & $0.003^{*}$ \\
\hline Ang-2/Ang-1 $(\log 10)^{a}$ & 2.630 & 1.207 to 5.729 & $0.015^{\star}$ & 2.384 & 1.061 to 5.360 & $0.036 * b$ \\
\hline
\end{tabular}

${ }^{*} \mathrm{p}<0.05$.

a tested separately from each other;

$\mathrm{b}$ In this model APACHE II remained significant in the multivariate model $(p=0.039)$.

Ang = Angiopoietin; APACHE II = Acute Physiology and Chronic Health Evaluation II; $\mathrm{Cl}=$ confidence interval; $\mathrm{CRP}=\mathrm{C}$-reactive protein; $f=$ female; $\mathrm{FiO}_{2}=$ fraction of inspired oxygen; $\mathrm{HR}=$ heart rate; $\mathrm{m}=$ male; $\mathrm{MAP}=$ mean arterial pressure; $\mathrm{PaO}_{2}=$ partial pressure of oxygen in arterial blood; SOFA = Sequential Organ Failure Assessment; VEGF = vascular endothelial growth factor.

our cohort was three-fold in the high Ang-2 $(>11.08 \mathrm{ng} / \mathrm{ml})$ group compared with the low Ang-2 group ( $\leq 11.08 \mathrm{ng} / \mathrm{ml})$. Of note, the 30-day survival of patients among the low Ang-2 group was $57 \%$, while it was $20 \%$ in the group of patients with high Ang-2 levels.

\section{Discussion}

The present study is a prospective clinical investigation of the prognostic value of circulating Ang-2 as a biomarker in critically ill patients. The results are that: critically ill patients are characterised by an excess of circulating Ang-2 in the presence of low Ang-1 and VEGF; Ang-2 correlates with severity of illness (APACHE II and SOFA scores), pulmonary dysfunc- tion $\left(\mathrm{PaO}_{2} / \mathrm{FiO}_{2}\right.$ and $\left.\mathrm{PaO}_{2}\right)$ and tissue hypoxia (lactate); using multivariate Cox proportional hazards regression analysis, Ang-2 was identified as the only independent predictor for survival in our cohort of medical ICU patients.

As a Weibel-Palade body-stored molecule, Ang-2 is released on endothelial stimulation by various factors, including complement, cytokines, fibrin, activated platelets and leucocytes, and changes in oxygenation or blood flow $[8,15]$. Orfanos and colleagues [25] and Ganter and colleagues [22] reported that in septic patients Ang-2 levels were associated with tumour necrosis factor-alpha levels and systemic hypoperfusion, respectively. In line with the latter finding, we detected a strong 
Figure 3

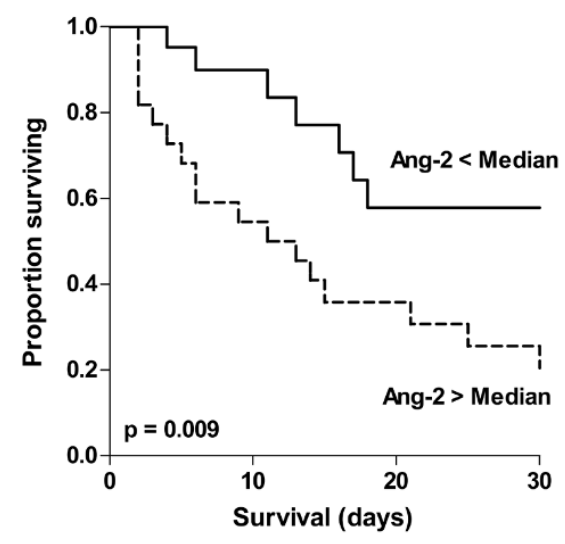

Kaplan-Meier curves of survival stratified to Angiopoietin (Ang) 2. (less versus greater than median; Log rank test $p=0.009$ ).

positive correlation between circulating Ang-2 and tissue hypoxia using lactate concentrations as a surrogate marker.

Little is known about the regulation of Ang-1 in critically ill patients. Experimental endotoxaemia has been shown to disrupt protective Ang-1/Tie-2 signalling by reducing Ang-1 and inducing Ang-2 expression [39]. In line with these results, admission levels of Ang-1 were markedly decreased in our patients. This finding is in apparent contrast to normal admission levels of Ang-1 in the aforementioned studies [22,23]. We assume that a decline in circulating Ang-1 is not an early feature in critically ill patients, but might reflect ongoing illness, as is often the case in medical patients compared with sudden onset of impairment in surgical and trauma patients. This interpretation fits with a recent cross-sectional study that showed low Ang-1 concentrations after lengthier mechanical ventilation in both, septic and non-septic ICU patients [21].

VEGF has been well characterised as an endothelial survival factor that prevents microvascular apoptotic cell loss in vitro [40]. In addition, the distinctive permeability-enhancing effects of VEGF underlie a significant role of this protein in acute vascular inflammation [41-43]. Both low and high VEGF concentrations have been found in critically ill patients, and its significance is not completely understood $[21,44,45]$. VEGF has been shown to modulate the effect of Ang-2 in a contextdependent fashion: when levels of VEGF are high, Ang-2 causes disassembly of inter-endothelial cell-cell contacts, whereas in the presence of low VEGF levels, Ang-2 induces endothelial cell death and vessel regression [16]. The latter constellation was present in our cohort, consistent with both a leaky and apoptotic endothelial cell phenotype in sepsis $[1,46]$.
Consistent with previous reports, a strong positive correlation between Ang-2 concentrations and APACHE II and SOFA scores was detected in our cohort $[23,25-27]$. Thus it is reasonable to assume that individual Ang-2 levels may reflect the extent of activated endothelial surface among all organ-specific vascular beds at the same time.

In line with Parikh and colleagues [26] and van der Heijden and colleagues [21], we found a significant association of high Ang-2 concentrations with low $\mathrm{PaO}_{2} / \mathrm{FiO}_{2}$ and $\mathrm{PaO}_{2}$ values. This supports the idea that excess Ang-2 is involved in the increase in pulmonary permeability, leading to ARDS [26]. However, no correlation between EVLWI and Ang-2 or VEGF was present in our cohort. Likewise, no correlation between EVLWI and Ang-2 was detected by van der Heijden and colleagues [21]. EVLWI as a surrogate marker for endothelial is probably an imperfect tool to detect permeability in mechanically ventilated patients. Indeed, Ang-2 correlated with pulmonary leak index assessed by the ${ }^{67}$ Gallium-labelled tranferrin method [21]. Surprisingly, no such correlation could be detected for CI, MAP, CVP, surrogate parameters of pre-load (ITBVI) and after-load (SVRI), as well as for vasopressor support in the present study. These data reveal an important limitation for Ang-2 as a quantitative marker for vascular permeability: high Ang-2 might be a surrogate parameter for increased capillary permeability per se, but is a poor marker for the absolute extent of vascular 'leakiness'.

In contrast, we could identify Ang-2 as the strongest predictor for survival in our cohort of medical ICU patients using a multivariate Cox model. In a large trauma cohort study [22], Ang2 correlated with mortality in a univariate analysis. In a surgical population with ARDS, Ang-2 predicted death with a similar discriminatory ability as the APACHE II score [23]. However, none of the aforementioned studies tested the independent predictive value of circulating Ang-2 compared with established predictors of outcome using a multivariate model. Ang2 indeed outperformed the APACHE II and SOFA scores, as well as several other predictors in our cohort. If validated in larger cohorts, Ang-2 might be a promising new marker for early outcome prediction and decision-making in critically ill patients.

It should be pointed out that there are several limitations of our study. The sample size of the present study was small and the 95\% confidence intervals for AUC are still wide. Also, we strictly included medical patients, thus our findings cannot be extrapolated to postoperative or surgical patient population. Future work will focus on the sensitivity and specificity between Ang-2 levels, severity scores, various cytokines and inflammatory markers in a larger ICU cohort including both, medical and surgical patients. 


\section{Conclusion}

In summary, a marked imbalance of the Ang/Tie system in favour of circulating Ang-2 is correlated with severity of illness and tissue hypoxia. High Ang-2 is probably a powerful independent biomarker of adverse clinical outcome in medical ICU patients. Further studies on the role of Ang-2 as a biomarker in critically ill patients are warranted.

\section{Key messages \\ - Ang-2 concentrations are increasingly higher across the following groups: healthy controls, patients without sep- sis, sepsis and septic shock. \\ - Excess Ang-2 was independently associated with infe- rior survival. \\ - Ang-2 may be used as an early and readily available new biomarker in the ICU.}

\section{Competing interests}

The authors declare that they have no competing interests.

\section{Authors' contributions}

PK had the initial idea, designed and supervised the research, analyzed the results, drew the diagrams and wrote the manuscript. AL established the immunoassays, performed the experiments, drew the diagrams and contributed to the manuscript. SD contributed to the idea, participated in the design of the study and contributed to the manuscript. $\mathrm{RH}$ established the immunoassays and supervised the experiments. $\mathrm{CH}, \mathrm{RF}$ and DF identified patients, collected samples, provided clinical data and reviewed the manuscript. $\mathrm{HH}$ supervised the project and reviewed the manuscript. JTK designed and supervised the research, enrolled patients and reviewed the manuscript. $\mathrm{PK}$ and $\mathrm{AL}$ contributed equally to the work and are both considered first authors

\section{Acknowledgements}

We are indebted to Dr. Ulrich Kretschmer and Dr. Thomas Ernst for extensive monitoring of the patients. We would also like to thank Dr. Ulrike Kümpers for critical discussion and proofreading of the manuscript.

\section{References}

1. Aird WC: The role of the endothelium in severe sepsis and multiple organ dysfunction syndrome. Blood 2003, 101:3765-3777.

2. Aird WC: Endothelium as an organ system. Crit Care Med 2004, 32:S271-S279.

3. Orfanos SE, Mavrommati I, Korovesi I, Roussos C: Pulmonary endothelium in acute lung injury: from basic science to the critically ill. Intensive Care Med 2004, 30:1702-1714.

4. Abraham E, Singer M: Mechanisms of sepsis-induced organ dysfunction. Crit Care Med 2007, 35:2408-2416.

5. Spronk PE, Zandstra DF, Ince C: Bench-to-bedside review: sepsis is a disease of the microcirculation. Crit Care 2004, 8:462-468.

6. Davis S, Aldrich TH, Jones PF, Acheson A, Compton DL, Jain V, Ryan TE, Bruno J, Radziejewski C, Maisonpierre PC, Yancopoulos GD: Isolation of angiopoietin-1, a ligand for the TIE2 receptor, by secretion-trap expression cloning. Cell 1996, 87:1161-1169.

7. Scharpfenecker M, Fiedler U, Reiss Y, Augustin HG: The Tie-2 ligand angiopoietin-2 destabilizes quiescent endothelium through an internal autocrine loop mechanism. J Cell Sci 2005, 118:771-780.

8. Fiedler U, Scharpfenecker M, Koidl S, Hegen A, Grunow V, Schmidt JM, Kriz W, Thurston G, Augustin HG: The Tie-2 ligand angiopoietin-2 is stored in and rapidly released upon stimulation from endothelial cell Weibel-Palade bodies. Blood 2004, 103:4150-4156.

9. Fiedler $U$, Reiss $Y$, Scharpfenecker $M$, Grunow V, Koidl $S$, Thurston G, Gale NW, Witzenrath M, Rosseau S, Suttorp N, Sobke A, Herrmann M, Preissner KT, Vajkoczy P, Augustin HG: Angiopoietin-2 sensitizes endothelial cells to TNF-alpha and has a crucial role in the induction of inflammation. Nat Med 2006, 12:235-239.

10. Kim I, Kim HG, So JN, Kim JH, Kwak HJ, Koh GY: Angiopoietin-1 regulates endothelial cell survival through the phosphatidylinositol 3'-Kinase/Akt signal transduction pathway. Circ Res 2000, 86:24-29.

11. Papapetropoulos A, Fulton D, Mahboubi K, Kalb RG, O'Connor DS, Li F, Altieri DC, Sessa WC: Angiopoietin-1 inhibits endothelial cell apoptosis via the Akt/survivin pathway. J Biol Chem 2000, 275:9102-9105.

12. Huang YQ, Li JJ, Hu L, Lee M, Karpatkin S: Thrombin induces increased expression and secretion of angiopoietin-2 from human umbilical vein endothelial cells. Blood 2002, 99:1646-1650.

13. Mandriota SJ, Pepper MS: Regulation of angiopoietin-2 mRNA levels in bovine microvascular endothelial cells by cytokines and hypoxia. Circ Res 1998, 83:852-859.

14. Fiedler U, Krissl T, Koidl S, Weiss C, Koblizek T, Deutsch U, Martiny-Baron G, Marme D, Augustin HG: Angiopoietin-1 and angiopoietin-2 share the same binding domains in the Tie-2 receptor involving the first Ig-like loop and the epidermal growth factor-like repeats. J Biol Chem 2003, 278:1721-1727.

15. Fiedler U, Augustin HG: Angiopoietins: a link between angiogenesis and inflammation. Trends Immunol 2006, 27:552-558.

16. Lobov IB, Brooks PC, Lang RA: Angiopoietin-2 displays VEGFdependent modulation of capillary structure and endothelial cell survival in vivo. Proc Natl Acad Sci USA 2002, 99:11205-11210.

17. Daly C, Pasnikowski E, Burova E, Wong V, Aldrich TH, Griffiths J, loffe E, Daly TJ, Fandl JP, Papadopoulos N, McDonald DM, Thurston G, Yancopoulos GD, Rudge JS: Angiopoietin-2 functions as an autocrine protective factor in stressed endothelial cells. Proc Natl Acad Sci USA 2006, 103:15491-15496.

18. Kim I, Kim JH, Moon SO, Kwak HJ, Kim NG, Koh GY: Angiopoietin-2 at high concentration can enhance endothelial cell survival through the phosphatidylinositol 3'-kinase/Akt signal transduction pathway. Oncogene 2000, 19:4549-4552.

19. Pickers $P$, Sprong T, Eijk L, Hoeven H, Smits $P$, Deuren M: Vascular endothelial growth factor is increased during the first 48 hours of human septic shock and correlates with vascular permeability. Shock 2005, 24:508-512.

20. Yano K, Liaw PC, Mullington JM, Shih SC, Okada H, Bodyak N, Kang PM, Toltl L, Belikoff B, Buras J, Simms BT, Mizgerd JP, Carmeliet $P$, Karumanchi SA, Aird WC: Vascular endothelial growth factor is an important determinant of sepsis morbidity and mortality. J Exp Med 2006, 203:1447-1458.

21. Heijden $M$ van der, Nieuw Amerongen GP, Koolwijk $P$, van Hinsbergh VW, Groeneveld AB: Angiopoietin-2, permeability oedema, occurrence and severity of ALI/ARDS in septic and non-septic critically ill patients. Thorax 2008, 63:903-909.

22. Ganter MT, Cohen MJ, Brohi K, Chesebro BB, Staudenmayer KL, Rahn P, Christiaans SC, Bir ND, Pittet JF: Angiopoietin-2, marker and mediator of endothelial activation with prognostic significance early after trauma? Ann Surg 2008, 247:320-326.

23. Gallagher DC, Parikh SM, Balonov K, Miller A, Gautam S, Talmor D, Sukhatme VP: Circulating angiopoietin 2 correlates with mortality in a surgical population with acute lung injury/adult respiratory distress syndrome. Shock 2008, 29:656-661.

24. Giuliano JS Jr, Lahni PM, Harmon K, Wong HR, Doughty LA, Carcillo JA, Zingarelli B, Sukhatme VP, Parikh SM, Wheeler DS: Admission angiopoietin levels in children with septic shock. Shock 2007, 28:650-654. 
25. Orfanos SE, Kotanidou A, Glynos C, Athanasiou C, Tsigkos S, Dimopoulou I, Sotiropoulou C, Zakynthinos S, Armaganidis A, Papapetropoulos A, Roussos C: Angiopoietin-2 is increased in severe sepsis: correlation with inflammatory mediators. Crit Care Med 2007, 35:199-206.

26. Parikh SM, Mammoto T, Schultz A, Yuan HT, Christiani D, Karumanchi SA, Sukhatme VP: Excess circulating angiopoietin2 may contribute to pulmonary vascular leak in sepsis in humans. PLoS Med 2006, 3:e46.

27. Lukasz A, Hellpap J, Horn R, Kielstein JT, David S, Haller H, Kumpers P: Circulating angiopoietin-1 and $\mathbf{- 2}$ in critically ill patients - development and clinical application of two new immunoassays. Crit Care 2008, 12:R94.

28. Levy MM, Fink MP, Marshall JC, Abraham E, Angus D, Cook D, Cohen J, Opal SM, Vincent JL, Ramsay G: 2001 SCCM/ESICM/ ACCP/ATS/SIS International Sepsis Definitions Conference. Intensive Care Med 2003, 29:530-538.

29. Ventilation with lower tidal volumes as compared with traditional tidal volumes for acute lung injury and the acute respiratory distress syndrome. The Acute Respiratory Distress Syndrome Network. N Engl J Med 2000, 342:1301-1308.

30. Sakka SG, Ruhl CC, Pfeiffer UJ, Beale R, McLuckie A, Reinhart K, Meier-Hellmann A: Assessment of cardiac preload and extravascular lung water by single transpulmonary thermodilution. Intensive Care Med 2000, 26:180-187.

31. Uchino $S$, Bellomo $R$, Morimatsu $H$, Sugihara $M$, French $C$, Stephens D, Wendon J, Honore P, Mulder J, Turner A: Pulmonary artery catheter versus pulse contour analysis: a prospective epidemiological study. Crit Care 2006, 10:R174.

32. Knaus WA, Draper EA, Wagner DP, Zimmerman JE: APACHE II: a severity of disease classification system. Crit Care Med 1985, 13:818-829.

33. Vincent JL, Moreno R, Takala J, Willatts S, de Mendonca A, Bruining $H$, Reinhart CK, Suter PM, Thijs LG: The SOFA (Sepsisrelated Organ Failure Assessment) score to describe organ dysfunction/failure. On behalf of the Working Group on Sepsis-Related Problems of the European Society of Intensive Care Medicine. Intensive Care Med 1996, 22:707-710.

34. Kumpers $\mathrm{P}$, Koenecke $\mathrm{C}$, Hecker $\mathrm{H}$, Hellpap J, Horn R, Verhagen W, Buchholz S, Hertenstein B, Krauter J, Eder M, David S, Göhring G, Haller H, Ganser A: Angiopoietin-2 predicts disease-free survival after allogeneic stem cell transplantation in patients with high-risk myeloid malignancies. Blood 2008, 112:2139-2148.

35. Mandriota SJ, Pyke C, Di Sanza C, Quinodoz P, Pittet B, Pepper MS: Hypoxia-inducible angiopoietin-2 expression is mimicked by iodonium compounds and occurs in the rat brain and skin in response to systemic hypoxia and tissue ischemia. $A m \mathrm{~J}$ Pathol 2000, 156:2077-2089.

36. Pichiule P, Chavez JC, LaManna JC: Hypoxic regulation of angiopoietin-2 expression in endothelial cells. J Biol Chem 2004, 279:12171-12180.

37. Witzenbichler B, Westermann D, Knueppel S, Schultheiss HP, Tschope C: Protective role of angiopoietin-1 in endotoxic shock. Circulation 2005, 111:97-105.

38. Mei SH, McCarter SD, Deng Y, Parker CH, Liles WC, Stewart DJ: Prevention of LPS-induced acute lung injury in mice by mesenchymal stem cells overexpressing angiopoietin 1. PLOS Med 2007, 4:e269.

39. Mofarrahi M, Nouh T, Qureshi S, Guillot L, Mayaki D, Hussain SN: Regulation of angiopoietin expression by bacterial lipopolysaccharide. Am J Physiol Lung Cell Mol Physiol 2008.

40. Gerber HP, McMurtrey A, Kowalski J, Yan M, Keyt BA, Dixit V, Ferrara N: Vascular endothelial growth factor regulates endothelial cell survival through the phosphatidylinositol 3'-kinase/Akt signal transduction pathway. Requirement for Flk-1/KDR activation. J Biol Chem 1998, 273:30336-30343.

41. Larcher F, Murillas R, Bolontrade M, Conti CJ, Jorcano JL: VEGF/ VPF overexpression in skin of transgenic mice induces angiogenesis, vascular hyperpermeability and accelerated tumor development. Oncogene 1998, 17:303-311.

42. Thurston G, Suri C, Smith K, McClain J, Sato TN, Yancopoulos GD, McDonald DM: Leakage-resistant blood vessels in mice transgenically overexpressing angiopoietin-1. Science 1999, 286:2511-2514.

43. Thurston G, Rudge JS, loffe E, Zhou H, Ross L, Croll SD, Glazer $\mathrm{N}$, Holash J, McDonald DM, Yancopoulos GD: Angiopoietin-1 protects the adult vasculature against plasma leakage. Nat Med 2000, 6:460-463.

44. Karlsson S, Pettila V, Tenhunen J, Lund V, Hovilehto S, Ruokonen $\mathrm{E}$ : Vascular endothelial growth factor in severe sepsis and septic shock. Anesth Analg 2008, 106:1820-1826.

45. Shapiro NI, Yano K, Okada H, Fischer C, Howell M, Spokes KC, Ngo L, Angus DC, Aird WC: A prospective, observational study of soluble FLT-1 and vascular endothelial growth factor in sepsis. Shock 2008, 29:452-457.

46. Haimovitz-Friedman A, Cordon-Cardo C, Bayoumy S, Garzotto M, McLoughlin M, Gallily R, Edwards CK III, Schuchman EH, Fuks Z, Kolesnick R: Lipopolysaccharide induces disseminated endothelial apoptosis requiring ceramide generation. J Exp Med 1997, 186:1831-1841. 